\title{
The prevalence and antimicrobial susceptibility patterns of beta-hemolytic streptococci colonizing the throats of schoolchildren in Assam, India
}

\author{
Utpala Devi, Prasanta Kumar Borah, Jagadish Mahanta \\ Regional Medical Research Centre, N.E. Region (ICMR), Assam, India
}

\begin{abstract}
Introduction: Studies on the carriage rate of beta-hemolytic streptococci among children form an important component of public health practice to prevent disease complications such as rheumatic fever/rheumatic heart disease, nephritis, and other local or systemic infections. Methodology: Throat swabs collected from asymptomatic schoolchildren were inoculated into appropriate media for isolation of betahemolytic streptococci. They were identified by standard biochemical methods and sero-grouped. Antibiotic sensitivity was evaluated using the Kirby-Bauer disk diffusion method.

Results and Conclusion: Beta-hemolytic streptococci were isolated from 106 (7.7\%) out of the 1,384 throat swabs and Group F was the predominant sero-group isolated. The highest resistance observed among all the beta-hemolytic streptococci was to trimethoprimsulfamethoxazole.
\end{abstract}

Key Words: Beta-hemolytic streptococci; schoolchildren; Assam, India

J Infect Dev Ctries 2011; 5(11):804-808.

(Received 06 August 2010 - Accepted 02 May 2011)

Copyright $(\odot 2011$ Devi et al. This is an open-access article distributed under the Creative Commons Attribution License, which permits unrestricted use, distribution, and reproduction in any medium, provided the original work is properly cited.

\section{Introduction}

The beta-hemolytic streptococci (BHS) belonging to Lancefield groups A,B,C,G and $\mathrm{F}$ are known to cause serious systemic infections worldwide [1-10]. BHS, particularly group A, are the cause of systemic syndromes such as streptococcal necrotizing fasciitis, toxic shock syndrome, puerperal fever, and more localized conditions such as erysipelas and tonsillitis. The BHS can colonize the throat of healthy carriers as commensals, serving as a reservoir for pathogen transmission.

There have been reports of emerging antimicrobial drug resistant strains among the $\beta$ hemolytic streptococci (BHS). Most alarming would be an increase in resistance to the older, most effective and less expensive antibiotics, such as penicillin [11-13]. Streptococci can be transmitted from person to person via aerosols after sneezing or coughing, and also via fomites. Crowded environments, which are often experienced in schools, refugee camps, and military units, are conducive to transmission. Knowledge about antibiotic resistance patterns prevalent in local geographical regions is important for clinicians to choose the most effective antibiotic for treatment. Studies that determine the carriage rate of BHS among children are important to public health practices to aid in the prevention of infections and their serious complications, such as rheumatic fever/rheumatic heart disease, nephritis, and local or systemic infections.

This study was designed to determine the carrier state of BHS, the prevalent sero-groups, and the antimicrobial susceptibility patterns to commonly used antibiotics among schoolchildren of Dibrugarh District of Assam, India.

\section{Methodology}

Study area and study subjects

Out of 1,631 schools in the Dibrugarh District, 99 schools were randomly selected for streptococcal screening after obtaining permission from the school authorities. Parents of the children were apprised about the role of BHS in colonizing the oral cavity and in their potential for causing disease. Before enrolment in the study, informed consent was obtained from the parents with the understanding that their children would undergo a simple throat swab culture to determine the presence of BHS. Children with no signs and symptoms of upper respiratory tract infection and no history of antibiotic therapy within the last two weeks were enrolled in the study. The 
Table 1. Distribution by age and sex of children colonized with $\beta$-hemolytic streptococci (BHS)

\begin{tabular}{lllll}
\hline $\begin{array}{l}\text { Age } \\
\text { in years }\end{array}$ & $\begin{array}{l}\text { Number of } \\
\text { subjects }\end{array}$ & Male & Female & $\begin{array}{l}\text { Total } \\
\text { BHS* }\end{array}$ \\
\hline $5-7$ & 271 & 198 & 73 & $33(12.17 \%)$ \\
$7-9$ & 260 & 161 & 99 & $14(5.38 \%)$ \\
$9-11$ & 252 & 134 & 118 & $19(7.53 \%)$ \\
$11-13$ & 360 & 168 & 192 & $26(7.22 \%)$ \\
$13-14$ & 241 & 100 & 141 & $14(5.8 \%)$ \\
Total & 1384 & 761 & 623 & 106 \\
\hline
\end{tabular}

study was approved by the Institute's Ethical Committee.

\section{Laboratory investigations}

Throat swabs from the students were inoculated on $5 \%$ sheep blood agar prepared using blood agar base (Hi Media, Mumbai, India). The inoculated plates were incubated at $37^{\circ} \mathrm{C}$ in a $\mathrm{CO}_{2}$ incubator and were observed for beta-hemolysis after 24 hours and 48 hours. BHS were processed by Gram stain, catalase test, and bacitracin sensitivity, and were sero-grouped using a latex agglutination assay (Hi Strep Latex Kit, Hi Media, Mumbai, India).

Susceptibility of isolates to penicillin-G (10U), erythromycin $(15 \mu \mathrm{g})$, cefotaxime $(30 \mu \mathrm{g})$, chloramphenicol (30 $\mu \mathrm{g})$, trimethoprimsulphamethoxazole (TMP-SMX) $(1.25 / 23.75 \mu \mathrm{g})$, and ofloxacin $(5 \mu \mathrm{g})$ were evaluated by the Kirby-Bauer disk diffusion method [14]. The antibiotic disks were obtained from Hi Media, and Streptococcus pneumoniae ATCC 49619 was utilized as the quality control strain. An overnight broth suspension of each test isolate was adjusted to a 0.5 McFarland's turbidity standard and was used to inoculate Mueller Hinton agar plates supplemented with 5\% sheep blood. Antibiotic disks were applied to the plates, incubated at $37^{\circ} \mathrm{C}$ for 18 hours in a $\mathrm{CO}_{2}$ incubator after which the diameters of the zones of inhibition were measured. Zone diameters were interpreted as susceptible, intermediate, or resistant according to the manufacturers' instructions and Clinical Laboratory Standards Institute (CLSI) guidelines [15].

\section{Results}

In total, 1,384 throats swabs were obtained from 761 boys and 623 girls ranging from five to 14 years old and 106 BHS (7.65\%) were isolated (Table 1). Students five to seven years of age were most frequently colonized with BHS $(12.17 \%)$ (Table 1) and the distribution of Lancefield groups within these age categories is shown in Table 2. Results indicate that group $\mathrm{F}(53.77 \%)$ was the predominant colonizer across all age groups. BHS groups $\mathrm{G}$ and $\mathrm{A}$ had similar colonization rates of $19.81 \%$ and $16.98 \%$, respectively. The least common colonizers were group C (5.66\%) and group B (3.77\%) (Table 2).

The susceptibility patterns of the different BHS subgroups isolated from the schoolchildren are depicted in Table 3. The group A isolates were 100\% susceptible to penicillin, chloramphenicol and ofloxacin, and very susceptible to erythromycin (94.4\%). Susceptibility to cefotaxime and TMP-SMX were $72.2 \%$ and $22.2 \%$, respectively. The four group $\mathrm{B}$ isolates tested were $100 \%$ susceptible to penicillin, chloramphenicol, cefotaxime, TMP-SMX and ofloxacin and one isolate was intermediate to erythromycin. All six group C BHS were $100 \%$ susceptible to erythromycin, chloramphenicol and ofloxacin; however, penicillin, cefotaxime and TMPSMX had low susceptibility rates of $50 \%, 66.7 \%$ and $0 \%$, respectively.

Susceptibility to the antimicrobial agents tested was lowest among the 57 group F BHS isolated (Table 3). The following pattern was observed: penicillin $54.4 \%$, erythromycin $87.7 \%$, cefotaxime $43.85 \%$, chloramphenicol $86 \%$ TMP-SMX $31.6 \%$, and ofloxacin $89.47 \%$. Among the 21 group G isolates, $80.95 \%$ were susceptible to penicillin, erythromycin, chloramphenicol and ofloxacin. Poor susceptibility was observed with cefotaxime $(42.85 \%)$ and TMP-SMX (14.3\%).

\section{Discussion}

This study determined that the prevalence of BHS is $7.7 \%$ among asymptomatic schoolchildren within the Dibrugarh District of Assam, India. A similar carrier rate of $8.3 \%$ was reported among 1,796 asymptomatic patients in an urban hospital in Croatia [7] and a prevalence of 6-21.6\% was reported from India $[16,17]$. In this study, we observed that the 
Table 2. Sero-group distribution of the $106 \beta$-hemolytic streptococci (BHS) isolated

\begin{tabular}{|l|l|l|l|l|l|}
\hline $\begin{array}{l}\text { Age in } \\
\text { years }\end{array}$ & $\begin{array}{l}\text { Group A } \\
\text { BHS* } \\
n(\%)\end{array}$ & $\begin{array}{l}\text { Group B } \\
\text { BHS } \\
n(\%)\end{array}$ & $\begin{array}{l}\text { Group C } \\
\text { BHS } \\
n(\%)\end{array}$ & $\begin{array}{l}\text { Group F } \\
\text { BHS } \\
n(\%)\end{array}$ & $\begin{array}{l}\text { Group G } \\
\text { BHS } \\
n(\%)\end{array}$ \\
\hline $5-7$ & $4(3.77)$ & $3(2.83)$ & $4(3.77)$ & $16(15.09)$ & $6(5.66)$ \\
\hline $7-9$ & $2(1.89)$ & $1(0.94)$ & $1(0.94)$ & $8(7.55)$ & $2(1.89)$ \\
\hline $9-11$ & $2(1.89)$ & 0 & $1(0.94)$ & $12(11.32)$ & $4(3.77)$ \\
\hline $11-13$ & $7(6.60)$ & 0 & 0 & $12(11.32)$ & $7(6.60)$ \\
\hline $13-14$ & $3(2.83)$ & 0 & 0 & $9(8.49)$ & $2(1.89)$ \\
\hline Total & $18 / 106(16.98)$ & $4 / 106(3.77)$ & $6 / 106(5.66)$ & $57 / 106(53.77)$ & $21 / 106(19.81)$ \\
\hline
\end{tabular}

*BHS $=$ beta-hemolytic streptococci

Table 3. Susceptibility patterns of the isolated beta-hemolytic streptococci $(n=106)$

\begin{tabular}{|c|c|c|c|c|c|}
\hline \multirow{2}{*}{$\begin{array}{c}\text { Antimicrobial } \\
\text { Agent } \\
\text { S, I, R* }\end{array}$} & \multicolumn{5}{|c|}{ BHS $^{* *}$ Groups } \\
\hline & $\begin{array}{l}\text { Group A } \\
n=18(\%)\end{array}$ & $\begin{array}{l}\text { Group B } \\
n=4(\%)\end{array}$ & $\begin{array}{l}\text { Group C } \\
n=6(\%)\end{array}$ & $\begin{array}{l}\text { Group F } \\
n=57(\%)\end{array}$ & $\begin{array}{l}\text { Group G } \\
n=21(\%)\end{array}$ \\
\hline \multicolumn{6}{|l|}{ Penicillin G } \\
\hline $\mathbf{S}$ & $18(100)$ & $4(100)$ & $3(50)$ & $31(54.4)$ & $17(80.95)$ \\
\hline I & 0 & 0 & $3(50)$ & $19(33.3)$ & $2(9.52)$ \\
\hline $\mathbf{R}$ & 0 & 0 & 0 & $7(12.3)$ & $2(9.52)$ \\
\hline \multicolumn{6}{|l|}{ Erythromycin } \\
\hline $\mathbf{S}$ & $17(94.4)$ & $3(75)$ & $6(100)$ & $50(87.7)$ & 17 (80.95) \\
\hline I & $1(5.6)$ & $1(25)$ & 0 & $5(8.8)$ & $4(19.05)$ \\
\hline $\mathbf{R}$ & 0 & 0 & 0 & $2(3.5)$ & 0 \\
\hline \multicolumn{6}{|l|}{ Cefotaxime } \\
\hline $\mathbf{S}$ & $13(72.2)$ & $4(100)$ & $4(66.7)$ & $25(43.85)$ & $9(42.85)$ \\
\hline I & $2(11.1)$ & 0 & $1(16.7)$ & $14(24.56)$ & $3(14.3)$ \\
\hline $\mathbf{R}$ & $3(16.7)$ & 0 & $1(16.7)$ & $18(31.6)$ & $9(42.85)$ \\
\hline \multicolumn{6}{|l|}{ Chloramphenicol } \\
\hline S & $18(100)$ & $4(100)$ & $6(100)$ & $49(86)$ & $17(80.95)$ \\
\hline $\mathbf{I}$ & 0 & 0 & 0 & $6(10.5)$ & $4(19.05)$ \\
\hline $\mathbf{R}$ & 0 & 0 & 0 & $2(3.5)$ & 0 \\
\hline \multicolumn{6}{|l|}{$\begin{array}{c}\text { Trimethoprim- } \\
\text { Sulfamethoxazole }\end{array}$} \\
\hline $\mathbf{S}$ & $4(22.2)$ & $4(100)$ & 0 & 18 (31.6) & $3(14.3)$ \\
\hline I & $2(11.1)$ & 0 & $1(16.7)$ & $2(3.5)$ & $2(9.5)$ \\
\hline $\mathbf{R}$ & $12(66.7)$ & 0 & $5(83.3)$ & 37 (64.9) & $16(76.2)$ \\
\hline \multicolumn{6}{|l|}{ Ofloxacin } \\
\hline $\mathbf{S}$ & $18(100)$ & $4(100)$ & $6(100)$ & $51(89.47)$ & $17(80.95)$ \\
\hline $\mathbf{I}$ & 0 & 0 & 0 & $3(5.26)$ & $4(19.05)$ \\
\hline $\mathbf{R}$ & 0 & 0 & 0 & $3(5.26)$ & 0 \\
\hline
\end{tabular}


highest prevalence rate was for group F BHS. These findings confirm those of other studies from various geographic locations that have demonstrated a higher prevalence of non-group A streptococci among healthy carriers [17]. In contrast, a report from India indicated a predominance of group $\mathrm{G}$ among various populations [17]. Therefore, the carriage rate of specific Lancefield groups of BHS can vary by geographic location.

In our study, BHS most frequently colonized the five to seven years age group, in agreement with reports from Nepal [18] and United Arab Emirates [19]. It can be speculated that a contributing factor to a lower colonization rate among older children may be related to host immunity that increases over time.

Both group A and non group A BHS are associated with acute pharyngitis $[1,3,7]$. However, group A pharyngitis is the most serious infection because of the severe sequelae, namely acute rheumatic fever and post streptococcal glomerulonephritis. Of importance, group G streptococci has been isolated from rheumatic fever patients and also from skin lesions of patients with acute glomerulonephritis. Group F, the predominant BHS observed in this study, has been associated with the following infections: dental abscess, brain abscess, meningitis, bacteremia, endocarditis, and pericarditis $[2,10,20]$.

Penicillin is used most often as the drug of choice for streptococcal pharyngitis. The emergence of resistance to this antibiotic would therefore be a major public health concern. The group A BHS in our study were $100 \%$ susceptible to penicillin and the lack of resistance among group A strains was also reported by others $[16,17]$. In contrast, only $54.4 \%$ of group $\mathrm{F}$ strains were penicillin-susceptible and these were also less susceptible to the other antimicrobial agents tested.

TMP-SMX had the highest antimicrobial resistance rate among the BHS tested in this study. Group A BHS exhibited $66.7 \%$ resistance to TMPSMX, which was higher than the $12.2 \%$ rate demonstrated in a study from North India [11]. The elevated resistance to this drug may be due to the fact that it is commonly prescribed in rural settings of the Assam state of India. Since all groups of BHS can cause serious disease, their identification and rates of resistance among asymptomatic carriers as well as those who are infected should be monitored. Knowledge of the drug susceptibility patterns of BHS and the prevalence of the Lancefield groups in specific geographic regions would assist clinicians in appropriate patient management and therapeutic regimen.

\section{References}

1. Tiemstra J and Miranda RLF (2009) Role of non-group A streptococci in acute pharyngitis. J Am Board Fam Med 22: 663-669.

2. Kabra R, Welke KF, Kernstine KH, Field FJ, Thompson BH, Vats HS, Weintraub NL (2005) Bacterial pericarditis due to group $\mathrm{F}$ streptococci as a complication of esophagomediastinal fistula. Ann Thorac Surg 79: 21322134.

3. Shet A and Kaplan E (2004) Addressing the burden of group A streptococcal disease in India. Indian J Pediatr 71: 41-48.

4. Mathur P, Kapil A, Das B (2004) Prevalence of group G \& group $\mathrm{C}$ streptococci at an Indian tertiary care centre. Indian J Med Res 120: 199-200.

5. Mohanty S, Kapil A, Mohapatra M, Das B, Dhawan B, Choudhury VP (2004) Group C streptococcal bacteremia: a case report from India. Southeast Asian J Trop Med Public Health 35: 877-878.

6. Malini A, Mohiyuddin SM, Brahmadathan KN, Prasad SR (2004) Extensive deep neck space abscess due to $\beta$ hemolytic group $\mathrm{G}$ streptococci- a case report. Indian J Med Microbiol 22: 263-265.

7. Begovac J, Bobinac E, Benic B, Desnica B, Maretic T, Basnec A, Kuzmanovic N (1993) Asymptomatic pharyngeal carriage of beta-haemolytic streptococci and streptococcal pharyngitis among patients at an urban hospital in Croatia. Eu J Epidemiol 9: 405-410.

8. Brahmadathan KN and Koshi G (1989) Importance of group $\mathrm{G}$ streptococci in human pyogenic infections. J Trop Med Hyg 92: 35-38.

9. Reid HF, Bassett DC, Poon-King T, Zabriskie JB, Read SE (1985) Group G streptococci in healthy school-children \& in patients with glomerulonephritis in Trinidad. J Hyg 94: 6168.

10. Wells DW and Keeney GT (1980) Group F Streptococcus associated with intrauterine pneumonia. Pediatrics 66: 820821.

11. Jain A, Shukla VK, Tiwari V, Kumar R (2008) Antibiotic resistance pattern of group A beta hemolytic streptococci isolated from North Indian children. Indian J Med Sci 62: 392-396.

12. Nabipour F and Tayarzadeh M (2005) Prevalence of betahemolytic Streptococcus carrier state and its sensitivity to different antibiotics among guidance-schoolchildren in Kerman, Iran. Am J Infect Dis 1: 128-131.

13. Nys S, Tjhie JH, Bartelds AI, Heijnen ML, Peeters MF, Stobberingh EE (2005) Erythromycin resistance in the commensal throat flora of patients visiting the general practitioner: a reservoir for resistance genes for potential pathogenic bacteria. Int J Antimicrob Agents 26: 133-137.

14. Bauer AW, Kirby WM, Sherris JC, Turck M (1996) Antibiotic susceptibility testing by standardized single disk method. Am J Clin Pathol 45: 493-496.

15. Clinical and Laboratory Standards Institute (2010) Performance standards for antimicrobial susceptibility testing; Twentieth informational supplement. CLSI document M100-S20. Wayne, PA: Clinical and Laboratory Standards Institute. 
16. Lloyd CA, Jacob SE, Menon T (2006) Pharyngeal carriage of group A streptococci in schoolchildren in Chennai. Indian J Med Res 124: 195-198.

17. Navneeth BV, Ray N, Chawda S, Selvarani P, Bhaskar M, Suganthi N (2001) Prevalence of beta hemolytic streptococci carrier rate among schoolchildren in Salem. Indian J Pediatr 68: 985-986.

18. Rijal KR, DhakalN, Shah RC, Timilsina S, Mahato P, S Thapa S, Ghimire P (2009) Antibiotic susceptibility of group A Streptococcus isolated from throat swab culture of schoolchildren in Pokhara, Nepal. Nepal Med Coll J 11: 238-240.

19. Shair SA (1990) Beta-hemolytic streptococci among primary schoolchildren in Al-Ain (UAE). World J Microbiol Biotechnol 6: 263-266.
20. Hasan RA and Abuhammour W (2004) [beta]-hemolytic group F streptococcal bacteremia in children. The Pediatr Infect Dis J 23: 468-470.

\section{Corresponding author}

Jagadish Mahanta, MD

Director

Regional Medical Research Centre

N.E. Region (ICMR), Post Box No-105

Dibrugarh-786001, Assam, India

Telephone: 91- 0373-2381494

Fax: 91-0373-2391748

Email: jmahanta@gmail.com

Conflict of interests: No conflict of interests is declared. 